\title{
UMA VIDA ILUMINADA: JONATHAN FOER E O FASCÍNIO PELO PASSADO
}

\author{
Gabriel Canuto Nogueira da Gama ${ }^{1}$
}

\begin{abstract}
Resumo: Neste artigo, o objetivo é analisar, à luz dos estudos sobre memória e esquecimento, o filme Everything is Illuminated, de Liev Schreiber, lançado em 2005. A obra cinematográfica traz reflexões pertinentes acerca da relação entre passado e presente, e memória individual e coletiva, além do paradigma da ressignificação da contemporaneidade retratada na figura do personagem central Jonathan Foer. Em primeira instância, busca-se estabelecer os traços da cultura pós-moderna do excesso de memória incorporados pelo protagonista. Depois, o estudo reflete sobre a relação dicotômica entre duas maneiras de lidar com o passado: o lembrar para não esquecer e o esquecer para não lembrar. A partir desses dois pontos de vista - de Jonathan Foer e do personagem Alex Perchov -, o objetivo é pensar os limites do esquecimento, o papel do historiador contemporâneo na perspectiva de Nietzsche, Benjamin e Agamben, e identificar o fenômeno da memória coletiva de Halbwachs na narrativa do filme.
\end{abstract}

Palavras-chave: Liev Schreiber; cinema; memória; história; esquecimento.

Abstract: This article aims to analyse, throughout memory and oblivion studies, the road movie Everything is Illuminated, by Liev Schreiber and released in 2005. The film brings relevant reflections about the relationship between past and present, and individual and collective memory, besides the "paradigm of the resignification of the contemporaneity" portrayed by the central-character Jonathan Foer. In first instance, the study seeks to establish the features of the overloaded memory in the post-modern culture personified in the main character. Afterwards, the finding reflects about the dichotomous relationship between two ways to deal with the past: "remind to not forget and to forget to not remind". From these two points of view - of Jonathan Foer and from the second character, Alex Perchov -, the objective is to think about the edges of oblivion, the role of the contemporary historian in Nietzsche, Benjamin and Agamben's perspectives, and identifies the phenomenon of the Halbwacks collective memory in the film's narrative.

Keywords: Liev Schreiber; cinema; memory; history; oblivion.

\footnotetext{
${ }^{1}$ Mestrando em Teoria da Literatura e Literatura Comparada junto ao Programa de PósGraduação em Estudos Literários da UFMG e Graduando em Bacharelado e Licenciatura (Português/Inglês) em Letras na PUC-MG. Membro do FULIA - Núcleo de Estudos sobre Futebol, Linguagem e Artes, da UFMG. E-mail: gabrielcngama@gmail.com
} 


\section{Introdução}

"Por que você coleciona coisas?" (SCHREIBER, 2005), pergunta Alexander Perchov ao protagonista, Jonathan Safran Foer, nos minutos de clímax do Road Movie, Everything is Illuminated. Após uma pausa dramática, o colecionador de memórias, interpretado pelo ator Elijah Wood, responde enfaticamente: "Por que tenho medo de esquecer" (SCHREIBER, 2005).

A obsessiva busca (rígida) pelo passado genealógico do colecionador judeu norte-americano, Jonathan Foer, é o tema central da obra cinematográfica, lançada em 2005, dirigida por Liev Schreiber, e baseada na obra homônima autobiográfica do protagonista, Everything is Illuminated. Em uma longa viagem pelo interior da Ucrânia, o objetivo do personagem central é descobrir a história da emigração de seu avô, Safran Foer, para os Estados Unidos, após a ocupação nazista no vilarejo judaico de Trachimbrod, mas, sobretudo, a aventura significa um ato de preservação de uma memória coletiva construída por seus familiares.

\section{Uma vida iluminada pelo passado e distante do real}

Com traços anacrônicos, Jonathan é um adolescente da pósmodernidade que, em gestos e gostos, se distancia do próprio tempo em que está. O seu peculiar vício em colecionar objetos materiais em sacos plásticos, principalmente os rastros deixados por seus familiares do passado, é uma forma de acalentar a sua angústia em não conseguir dar conta do vivido, isto é, de um espaço-presente que parece ser insustentável e lacunar.

Jonathan é o retrato de um sujeito contemporâneo apaixonado pelo passado que necessita lembrar para não esquecer. Um jovem que deseja presentificar o tempo, e, pela via dos registros e dos testemunhos, legitimar a própria existência para construir um futuro. Um personagem, portanto, que representa a ânsia de uma geração pós-moderna imersa em uma intermitente busca por sentidos. 
A sua dependência por objetos remete a uma das críticas construídas por Andreas Huyssen em Seduzidos pela memória (2000), quando o teórico literário alemão expõe a problemática do excesso de monumentalizações em uma idade midiática, seja de ordem individual através da coleção de acervos pessoais, ou pela revalorização de museus, monumentos e memoriais, anteriormente negligenciados no período modernista. Tidos como redentores, tais locais de memória passam a se constituírem como estratégias preponderantes para lidar com o indizível, o irrepresentável, e, ainda, servirem como uma espécie de memória armazenada.

Numa época em que a noção de memória se transferiu para o domínio dos chips de silício, dos computadores e das histórias de ficção científica sobre cyborgs, os críticos lamentam rotineiramente a entropia da memória histórica, definindo a amnésia como perigoso vírus cultural criado pelas novas tecnologias de mídia. Quanto maior é a memória armazenada em bancos de dados e acervos de imagens, menor é a disponibilidade e a habilidade da nossa cultura para se engajar na rememoração ativa, pelo menos ao que parece (HUYSSEN, 2000, p. 67)

O cenário criticado por Huyssen é de um mundo caracterizado pelo excesso de memória, cuja constância é a vontade irrefreável de representar, replicar, reproduzir, recodificar, a todo o tempo, o passado. No paradigma da era pós-moderna, as memórias individuais e coletivas estão sendo afetadas por uma nova temporalidade, devido ao fenômeno da aceleração do tempo, em decorrência de uma vida cada vez mais material, regida pela lógica do consumo e do lucro, pela profusão de imagens e informações subsidiadas por um mundo midiático. O passado tem se transportado para o presente, constituindo assim uma inédita noção de "passado-presente".

O encurtamento temporal do passado e do presente - a ideia de "simultaneidade" nas palavras de Huyssen - culmina em uma inevitável destruição do espaço. O resultado é a perda da referencialidade no real e, consequentemente, o apagamento das fronteiras entre fato e ficção. O fascínio pela musealização, pelos passados rememorados, são influenciados por esse novo fenômeno temporal da era contemporânea. Não obstante, a figura de Jonathan no filme é tão paradigmática. Quanto mais a memória vai sendo 
armazenada nestes diferentes tipos de dispositivos, "mais o passado é sugado para a órbita do presente" (HUYSSEN, 2000, p. 67).

É diante de um mundo imediatista, acumulado por infindáveis informações diversificadas e da rápida obsolescência das coisas, que emerge um apelo para um retorno à rememoração e ao fascínio pelo passado como efeitos compensatórios de uma amnésia patológica e global.

Talvez ele [o interesse pelo passado] deva ser levado a sério como um modo de diminuir um pouco a velocidade da modernização, como uma tentativa, embora frágil e cheia de contradições, de atirar salva-vidas ao passado e contrabalançar a notória tendência de nossa cultura à amnésia, sob o signo do lucro imediato e da política do curto prazo. [...] A permanência do monumento e do objeto de museu, antes criticada como reificação mortificadora, assume um papel diferente numa cultura dominada pela fugacidade da imagem na tela e pela imaterialidade das comunicações (HUYSSEN, 2000, pp. 76-77)

\section{Lembrar para não esquecer $x$ Esquecer para não lembrar}

Se, para Jonathan, colher objetos materiais e imateriais durante sua jornada serve como preenchimento do seu passado-presente e, principalmente, uma alternativa ao não-esquecimento, o ato de negar o passado foi a maneira encontrada pelo avô do narrador, companheiro e tradutor na viagem de Jonathan, Alex Perchov, em lidar com a sua própria história. Depois de sobreviver a um fuzilamento quando era judeu, o avô decidiu apagar a sua identidade para dar conta de viver futuramente.

Alex Perchov, ao reviver o seu passado judeu em Trachimbrod pelo testemunho da irmã de Augustine, uma jovem que salvou o avô de Jonathan, se reconecta com a identidade que por décadas foi abandonada. O memorial em homenagem aos 1.024 mortos pelo massacre de 18 de março de 1942, além das caixas de lembranças e coleções guardadas cuidadosamente como 
pistas do passado por essa irmã de Augustine, a uma única pessoa que ainda permanece no vilarejo, serviram como suportes de memória para reacender o presente da família de Perchov e o passado de Jonathan.

O filme retrata as diferentes maneiras de se lidar com um fato traumático. Enquanto um personagem deseja lembrar para não esquecer, o outro deseja esquecer para não lembrar. A própria condição alegada pelo avô sobrevivente do massacre de uma falsa cegueira foi um artifício encontrado por ele para negar as suas origens.

Seligmann-Silva (1999) discorre, no ensaio "Reflexões sobre a memória, a história e o esquecimento", acerca da importância da lembrança e do esquecimento em determinadas situações históricas. Ao distinguir os dois atos, o pesquisador toma como referência as noções dicotômicas entre o a-histórico e o histórico em Friedrich Nietzsche como fundamentalmente necessárias para a vida de cada ser humano:

Defender como Nietzsche o tempo certo para se esquecer e o tempo certo para se lembrar pode levar à ideia inocente de que podemos controlar nossa memória. A historiografia decerto estaria mais próxima desse modelo: ela - na sua versão moderna - se quer não apenas imparcial e fria, mas também capaz de arquivar todos os acontecimentos (e era esse aspecto total da história que Nietzsche visou com sua crítica) (SELIGMANN-SILVA, 1999, pp. 61-62)

A ideia nietzschiana de pensar em esquecer na hora certa e de recordar na hora certa, bem como do valor do esquecimento, está contido, em partes, na segunda dissertação de Genealogia da moral. No livro, o filósofo alemão afirma que o esquecimento é uma força inibidora ativa e positiva, pois dá a oportunidade de experimentar algo novo como se propiciasse uma espécie de tabula rasa da consciência - um começar do zero sempre para que haja constantemente um lugar para o recomeço. De acordo com Nietzsche, e ratificado no ensaio de Seligmann-Silva (1999), a verdade (do grego aletheia) só poderá advir do esquecimento e não da memória.

[...] não poderia haver felicidade, jovialidade, esperança, orgulho, presente, sem o esquecimento [...] Precisamente esse animal que necessita esquecer, no qual o esquecer é uma força, uma forma de saúde forte, desenvolveu em si uma faculdade oposta, uma memória, com cujo auxílio o 
esquecimento é suspenso em determinados casos - nos casos em que se deve prometer [...] (NIETZSCHE, 2015, p. 43)

É interessante notar a gradativa mudança de comportamento psicológico de Perchov durante a viagem aos recônditos da Ucrânia. Antes de chegar a Trachimbrod, ele teve a sua primeira reconexão com o passado recalcado ao rever destroços de tanques da Segunda Guerra Mundial em um determinado lugar da estrada. A partir daquele choque, o avô do narrador, de um sujeito carrancudo e amargurado, vai se transformando em um ser humano reflexivo e sensível, até desatinar em um desabafo de emoções reprimidas na cena em que a irmã de Augustine descreve o fatídico aniquilamento dos judeus. Ela relata:

- Eles nos puseram em filas. Fizeram listas. Tudo era muito organizado. Incendiaram a sinagoga. Desenrolaram a Torá no chão e mandaram os homens cuspirem nela. [...] Era a Torá deles que estava na sinagoga desde que o primeiro rabino a trouxe 300 anos antes. O primeiro foi Yosef. Ele era sapateiro. Apontaram uma arma para a cabeça da filha dele e o mandaram cuspir sobre a Torá. Rasgaram, chutaram e fizeram de tudo o que mandaram. Todos eles cuspiram exceto meu pai. Depois minha irmã. Ela estava grávida. Apontaram uma arma na barriga dela. Disseram que matariam o bebê se o pai dela não cuspisse. Ele não conseguiu. Ele se recusava a cuspir (SCHREIBER, 2005)

Após a visita a Trachimbrod, Perchov decide se suicidar em uma banheira do hotel em que estavam hospedados, em um possível gesto de reconciliação com o passado, como o próprio narrador refletiu ao final do filme.

Em um cômputo geral, a busca rígida de Jonathan por um passado reacendeu, ou melhor, nas palavras do próprio título da obra cinematográfica, "iluminou" o presente da pitoresca família ucraniana de Perchov, o neto, que acompanhou o protagonista em sua jornada de recuperação da memória de seus parentes. Isto é, a própria perseguição da memória serviu como um elo entre passado e futuro e, até mesmo, uma ligação entre memórias coletivas de duas famílias distantes geograficamente, todavia, aproximadas pelo fenômeno da história. "Como indivíduos e sociedades, precisamos do passado para 
construir e ancorar nossas identidades e alimentar uma visão de futuro" (HUYSSEN, 2000, p. 67).

O temor de Jonathan em esquecer é o medo do esquecimento coletivo presente na contemporaneidade, por isso, a figura do monumento, seja como local de memória, ou materializado em coisas e lembranças pequenas, é o que legitima e mantém viva a relação entre passado e futuro.

Jonathan é a possibilidade de ser a memória herdada do avô. É a chance de evitar que seu predecessor passe de senhor da própria memória para um escravo dela mesma, como Achugar teoriza em Planetas sem boca: escritos efêmeros sobre arte, cultura e literatura:

[...] o que deve ser preservado, recordado, transmitido e o que deve ser descartado, esquecido, enterrado? E, além disso, a partir de onde e de quem elaborar essa avaliação? [...] A eventual angústia que essas perguntas podem transmitir tem a ver, como assinalamos antes, com a mais que provável possibilidade de nos transformarmos de senhores da nossa memória em escravos ou "colonizados" - para evocar um termo de particular e atual autoridade - o da memória de outros (ACHUGAR, 2006, pp. 176-177)

\section{Jonathan: um contemporâneo historiador benjaminiano}

Se pouco depois do evento traumático do Holocausto a necessidade era esquecer, enterrar os acontecimentos, silenciar-se, para dar conta do vivido, o protagonista é de uma geração pós-moderna, cujo um dos principais objetivos é o paradigma da ressignificação.

A partir da década de 1980, a influência de diferentes saberes epistemológicos diversos, desde a filosofia hermenêutica, a psicologia lacaniana, a teoria marxista, à desconstrução do pós-estruturalismo derridiano e deleuziano e as correntes literárias mais recentes, como o novo historicismo, a teoria feminista e a pós-colonial, são o retrato de um tempo que deseja recontar a história não mais pela linearidade positivista, mas pela via da fragmentação.

Se o século XIX sofreu de "história demais", a nossa pósmodernidade sofre de "fim da história", de "fim da 
temporalidade", em suma, parafraseando Vidal-Naquet, ela sofre do "inexistencialismo". A tarefa da memória deve ser compartilhada tanto em termos na memória individual e coletiva como também pelo registro (acadêmico) da historiografia (SELIGMANN-SILVA, 1999, p. 63)

Jonathan é o símbolo de um novo tempo que pretende desenterrar histórias, rever o cânone, revalorizar a história oral e os testemunhos, reconstruir a história oficial dando espaço a vozes historicamente marginalizadas e silenciadas, ou seja, emergir as memórias subterrâneas como Pollak (1989) salienta no ensaio "Memória, esquecimento e silêncio":

Ao privilegiar a análise dos excluídos, dos marginalizados e das minorias, a história oral ressaltou a importância de memórias subterrâneas que, como parte integrante das culturas minoritárias e dominadas se opõem à "memória oficial", no caso a memória nacional [...] A memória entra em disputa (POLLAK, 1989, p. 4)

Friedrich Nietzsche e Walter Benjamin foram críticos de um tipo de historicismo do século XIX em que, ao contrário de valorizar o novo mediante ao esquecimento, se baseava em uma concepção de história como uma unidade linear. A crítica desses filósofos consiste em pensar a história de uma maneira permanentemente fragmentária, envolta de memórias plurais e inacabadas. Eles reiteram que é preciso dar vazão às memórias individuais e coletivas reprimidas pela história oficial, pois a pretensão ousada da historiografia positivista em buscar restituir o passado integralmente é impossível. Segundo Seligmann-Silva (1999), não há como fazer uma tradução total do que está atrás e, por isso, atenta para a necessidade de superar essa tradição canônica do fascínio pela representação.

A crítica ao modelo linear e rígido do historicismo para uma nova temporalidade - fragmentária e dos registros individuais e coletivos da memória - é, de alguma maneira, a passagem do paradigma da modernidade para o contemporâneo como Huyssen (2000) desenvolveu em Seduzidos pela memória. O outrora deslumbramento dos sentimentos dos modernistas, o êxtase pelo vir-a-ser e a negligência ao passado foram gradativamente sendo substituídos por um pensamento cético em relação à ideia central historicista 
do progresso, em função dos acontecimentos sombrios da primeira metade do século XX, como o Holocausto e as duas Guerras Mundiais.

Em uma era da presentificação do espaço-tempo, o passado só será construído a partir do presente. A historiografia tem de ser repensada pelo caminho da fragmentação, das ruínas, pela análise dos rastros das memórias, e este é que deve ser, do ponto de vista benjaminiano, o papel do "historiador anti-historicista": de apresentar pela reminiscência e não representar pela totalidade:

Tanto para Benjamin como para Halbwacks, o preceito historicista da restituição e representação total do passado deve ser posto de lado. Graças ao conceito de memória, eles trabalham não no campo da re-presentação, mas sim da apresentação enquanto construção a partir do presente. "A lembrança", afirma Halbwacks, "é em legal medida uma reconstrução do passado com ajuda de dados emprestados do presente e, além disso, preparada por outras reconstruções feitas em épocas anteriores e de onde a imagem de outrora se manifestou bem alterada". Benjamin, por sua vez, afirma que o historiador materialista - ou seja, anti-historicista - deve visar a construção de uma montagem: vale dizer, de um collage de escombros e fragmentos de um passado que só existe na sua configuração presente de destroço (SELIGMANN-SILVA, 1999, p. 70)

É possível imaginar Jonathan como esta figura que deseja reacender o passado à luz do presente. Um ser contemporâneo anti-historicista que, como Giorgio Agamben postula em $O$ que é o contemporâneo?, "aquele que mantém fixo o olhar no seu tempo para nele perceber não as luzes, mas o escuro" (AGAMBEN, 2009, p. 62). Isto é, fazendo uma alusão ao mito da caverna platônico, aquele que tem a consciência de estar na caverna, mas, ao mesmo tempo, sabe ver o obscuro do seu tempo e que é capaz de escrever, no sentido amplo, em meio às trevas do presente.

Segundo Agamben (2009), Nietzsche vai dizer que o homem verdadeiramente contemporâneo é aquele que se desloca de seu próprio tempo por não estar adequado às dadas pretensões, por isso, ele é algo como um ser inatual capaz de apreender e entender o seu tempo mais do que outros. É interessante como o diretor Liev Schreiber consegue apresentar Jonathan como esse ser fora do seu tempo - anacrônico nas vestimentas, no estilo de 
vida jovial (alheio às drogas, indiferente ao sexo e aos vícios da juventude), e no próprio modo de pensar. Um protagonista que, como Nietzsche prevê, deseja acertar as contas do seu tempo e tomar posição em relação ao presente sem ser devorado pela "febre da história" (AGAMBEN, 2009, p. 58).

Essa maneira anacrônica de enxergar o mundo do verdadeiramente contemporâneo não significa que este ser viva alienadamente, como se não tivesse consciência do próprio tempo. Ele apenas tem o discernimento de que não se pode fugir de onde está, mesmo odiando. Contemporâneo, portanto, passa a ser aquele que não se deixa cegar pelas luzes de seu tempo. Aquele ser que não se aliena diante dos sistemas de poder totalizantes. Aquele que se interessa pelo escuro do presente, deseja interpelá-lo e, através de um passado transformado, ser capaz de responder às trevas do agora.

Essa não-consciência, essa discronia, não significa, naturalmente, que contemporâneo seja aquele que vive num outro tempo, um nostálgico que se sente em casa mais na Atenas de Péricles, ou na Paris de Robispierre e do marquês de Sade do que na cidade e no tempo em que lhe foi dado viver. Um homem inteligente pode odiar o seu tempo, mas sabe, em todo o caso, que lhe pertence irrevogavelmente, sabe que não pode fugir a seu tempo (AGAMBEN, 2009, p. 59)

O filme rompe com a concepção historiográfica positivista, assim como pretendia teoricamente Nietzsche e Benjamin, e trabalha com a questão da memória coletiva baseada em um novo tipo de historiografia à luz da memória pelos testemunhos e não em registros históricos frios. Em Uma vida iluminada, a memória coletiva se expressa a todo tempo por objetos materiais de ordem familiar ou da experiência local, em monumentalizações e lugares de memória.

A obstinada busca de Jonathan pelo passado e de manter viva a memória de seu avô representa a confluência das lembranças individuais e das coletivas. Mesmo que não tenha vivido o ocorrido, Jonathan tem a chance de experienciar, indiretamente, por meio dos rastros que sobraram do passado, e ainda ter a oportunidade em dar prosseguimento às memórias, ou seja, em manter a identidade da sua família. A memória, portanto, é fundamentalmente coletiva, como Kessel (2008) explicita em seu artigo "Memória e memória 
coletiva", "o indivíduo carrega em si a lembrança, mas está sempre interagindo com a sociedade, seus grupos e instituições. É no contexto destas relações que construímos as nossas lembranças" (KESSEL, 2008, p. 3).

Segundo Halbwachs (1990), citado por Martins (2007), as lembranças de um indivíduo permanecem coletivas e serão lembradas por outros, mesmo que os fatos não tenham sido vividos por todos - como acontece com a memória do avô Foer em Jonathan. A ideia de que o passado permanece vivo, mesmo que de maneira reconstruída, foi a reflexão que o narrador, Alex Perchov, chegou após ter realizado a busca rígida com Jonathan. Logo na primeira cena do filme, ele revela que sua visão em relação ao passado havia mudado: "Eu era da opinião de que o passado era passado e, como tudo que não faz parte do presente, deveria ficar enterrado junto com nossas lembranças. Mas isso foi antes do começo da nossa busca muito rígida, antes de eu conhecer o colecionador Jonathan Safran Foer" (SCHREIBER, 2005).

Em suma, o sentimento de identidade, tanto no sentido individual, como coletivo, está intrinsecamente relacionado a esta memória herdada de um acontecimento traumático. No caso do aniquilamento dos judeus em Trachimbrod, no período da invasão nazista da Ucrânia, a lembrança traumática do fato, segundo o pensamento de Halbwachs (1990), é da ordem histórica (coletiva), por isso, é memorialmente narrada por um grupo imenso de vítimas, até mesmo por aqueles que não fizeram parte direta dos fatos, mas que herdaram a memória dos que sofreram, como é o caso do protagonista de Uma vida iluminada em relação ao passado de seu avô. 


\section{REFERÊNCIAS}

ACHUGAR, Hugo. O lugar da memória: a propósito de monumentos (motivos e parênteses). In: Planetas sem boca: escritos efêmeros sobre arte, cultura e literatura. Trad. Lyslei Nascimento. Belo Horizonte: Editora UFMG, 2006, p. 167-183.

AGAMBEN, Giorgio. O que é o contemporâneo?. In: 0 que é o contemporâneo e outros ensaios. Trad. Vinicius Nicastro Honesko. Chapecó: Argos, 2009, pp. 55-76.

HALBWACKS, Maurice. A Memória Coletiva. São Paulo: Vértice, 1990.

HUYSSEN, Andreas. Seduzidos pela memória: arquitetura, monumentos e mídia. Rio de Janeiro: Aeroplano, 2000.

KESSEL, Zilda. Memória e memória coletiva. 2008. Disponível em: <http://www.memoriaeducacao.hpg.ig.com.br>. Acesso em: 22 jul. 2009.

MARTINS, Estevão C. de Rezende. O enigma do passado: construção social da memória histórica. Textos de História, v. 15, n. 1/2, pp. 35-48, 2007. Disponível em: http://www.unb.br/ih/novo_portal/portal_his/pos_graduacao/arquivos/revista/vol ume_15_1_e_2/por_partes/textos_de_historia_3.pdf; Acesso em: 08 jul. 2009. NIETZSCHE, Friedrich. Genealogia da moral. São Paulo: Companhia de Bolso, 2009.

POLLAK, Michael. Memória, esquecimento e silêncio. Estudos Históricos. Rio de Janeiro, v. 2, n. 3, pp. 3-15, 1989.

SCHREIBER, Liev. Everything is Illuminated. USA, cor, 2005, 105 min.

SELIGMANN-SILVA, Márcio. Reflexões sobre a memória, a história e o esquecimento. In: (org.). História, memória, literatura: o testemunho na era das catástrofes. Editora Unicamp, 1999, pp. 59-89. 